\title{
Meristic Variation in Golden Redfish, Sebastes marinus, Compared to Beaked Redfishes of the Northwest Atlantic*
}

\author{
I-Hsun $\mathrm{Ni}$ \\ Department of Fisheries and Oceans, Fisheries Research Branch \\ Northwest Atlantic Fisheries Centre, P. O. Box 5667 \\ St. John's, Newfoundland, Canada A1C 5X1
}

\begin{abstract}
Counts of the vertebral elements in 3,611 specimens and the anal and dorsal fin rays in 1,379 specimens were utilized to examine meristic variation in S. marinus in the Northwest Atlantic from West Greenland to the Grand Bank-Gulf of St. Lawrence, for comparison with data reported in similar studies of the beaked redfishes, $S$. mentella and $S$. fasciatus. The $x^{2}$-test of independence for meristic frequencies showed no significant differences between sexes or among depth zones except for significant depth variation of anal fin-ray and dorsal fin-ray frequencies on Flemish Cap. Geographic variation in S. marinus meristics was less than in the beaked redfishes. S. marinus was found to be similar to $S$. mentella in having 30 vertebrae (excluding urostyle), 8 anal fin rays and 15 dorsal fin rays, whereas $S$. fasciatus usually has 29,7 and 14 elements respectively. The recently-adopted common name "golden redfish" is considered to be appropriate for $S$. marinus.
\end{abstract}

\section{Introduction}

The classification of Northwest Atlantic redfishes, Sebastes sp., has been confused for many years. Templeman and Sandeman (1957) and Templeman (1959) described two types of redfish in the Newfoundland area: the marinus-type, usually found at shallow depths $(<300 \mathrm{~m})$, is orange or yellowish red in color, has relatively small eyes, and possesses a weaklydeveloped, blunt symphyseal knob on the lower jaw; and the mentella-type, usually found at greater depths, is bright red in color, has relatively large eyes, and possesses a well-developed, long pointed chin. This distinction was confounded by the discovery of a third redfish species, S. fasciatus (Barsukov, 1968). Morphological differences between S. mentella and S. fasciatus were described subsequently by Barsukov (1972), Barsukov and Zakharov (1972), Litvinenko $(1974,1980)$ and Templeman (1980). Ni (1981a, 1981b) supported the existence of $S$. fasciatus, concluded that meristics were good discriminators for separating the two beaked redfishes, $S$. mentella and S. fasciatus, and provided morphological guidelines for their separation. Ni (1982) described the temporal, depth and geographic variation of meristics in the beaked redfishes, suggesting that $S$. fasciatus occurs on the Scotian Shelf and the Grand Bank areas whereas S. mentella occurs largely in the Gulf of St. Lawrence, off Labrador and northward off Baffin Island. However, the status of $S$. marinus in the classification scheme of redfishes is unclear because of the difficulty in obtaining enough specimens of the three species from the same depth and locality to employ discriminant analysis. In this paper, the sexual, depth and geographic variation in vertebral, anal fin-ray and dorsal fin-ray frequencies in $S$. marinus are examined and the meristic differences among the three Northwest Atlantic redfish species are discussed.

\section{Materials and Methods}

The elements of 3,611 vertebral columns and the anal and dorsal fin rays of 1,379 specimens were counted in $S$. marinus samples collected during 1957-69 in the Northwest Atlantic from Davis Strait southward to the Scotian Shelf. Grouping of the data by the Northwest Atlantic Fisheries Organization (NAFO) divisions (subareas in the Baffin Island-West Greenland region) provided a convenient partition of the continental shelf into areas which facilitated comparison with published data on beaked redfishes $(\mathrm{Ni}$, 1982). S. marinus occurs rarely off northern Labrador (Div. 2GH), in the Gulf of St. Lawrence (Div. 4ST) and on the Scotian Shelf (Div. 4VWX) (Ni and McKone 1983), and no analysis could be performed for these areas.

Samples were collected from bottom otter-trawl catches of research vessels at depths from 100 to $500 \mathrm{~m}$ along the slope of the continental shelf. The data was arbitrarily divided into four depth strata $(<200$, $200-299,300-399, \geqslant 400 \mathrm{~m}$ ) for the study of variation in meristics with depth. Vertebral counts excluded the urostyle. Anal fin-ray counts were determined from the number of pterygiophores connected with the anal rays, the bifurcated ray elements associated with the posteriormost pterygiophore being counted as one ray.

Variation of the meristic frequencies in each NAFO division by sex and depth interval was analyzed by

\footnotetext{
* Based on a paper presented at the NAFO Special Session on "Stock Discrimination in Marine Fishes and Invertebrates of the Northwest Atlantic",
} held at the Bedford Institute of Oceanography, Dartmouth, Nova Scotia, Canada, during 8-10 September 1982. 
using the BMDP4F computer program of Dixon et al. (1981), involving the application of Pearson's $x^{2}$-test, with Yate's correction when the frequency table was $2 x$ 2. Geographic variation was deduced from the patterns of means and modes of the meristic frequencies.

The meristic characters of $S$. marinus were compared with those of the beaked redfishes $(\mathrm{Ni}, 1982)$ by using the BMDP3D computer program of Dixon et al. (1981), involving Levene's w-test for variances and the appropriate t-test for means. The group means of the three meristic characters could then be tested simultaneously by the multivariate F-statistic, utilizing the Hotelling $T^{2}$ and the Mahalanobis $D^{2}$ tests (Morrison, 1976).

\section{Results}

\section{S. marinus meristics}

The meristic frequencies illustrated in Fig. 1 are those for which statistical parameters are summarized in Table 1. To justify combination of the data for males and females, $x^{2}$ tests were applied to the meristic frequencies for each NAFO area and for all areas combined, with no resultant significant difference between sexes ( $P>0.05$ in all cases). Insofar as the data were adequate to test for variation in meristic frequencies by depth zones $(<200,200-299,300-399, \geqslant 400)$, significant differences were evident for both anal and dorsal fin rays in the samples from Div. 3M (Flemish Cap) and for all three meristic characters when data for all areas were combined (Table 1).

The dominant vertebral count was 30 in all areas (Fig. 1), with only slight variation in the means (29.97-30.16) despite the great variation in sample size (Table 1). Except for the relatively high percentage of abnormal vertebrae (3.57\%) in S. marinus from Div. 3L (northern Grand Bank), no particular geographic trend was evident.

The mode of the anal fin-ray frequencies was 8 in most areas, except Subarea 1 (West Greenland) and Div. 3K (Northeast Newfoundland) where 8 and 9 rays were both prevalent and in Subarea 0 (Baffin Island) where the dominant number was 9 rays (Fig. 1). Unlike the vertebral averages, the mean anal fin-ray counts exhibited a wider range (8.00-8.69), with a decreasing trend from north to south (Table 1).

The dorsal fin-ray frequencies were dominated by a mode at 15 in most areas, except Div. 2J (southern Labrador) and Div. 30 (southwestern Grand Bank) where 14 rays were almost as prevalent as 15 and in

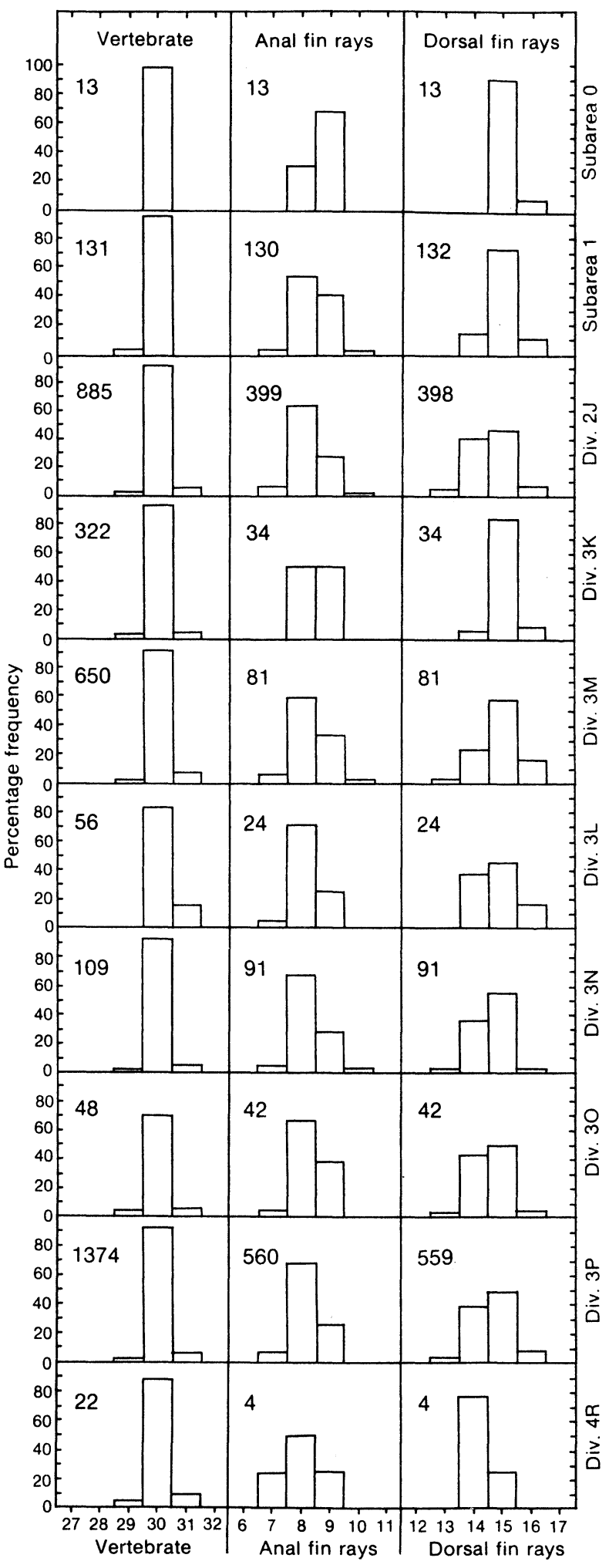

Fig. 1. Vertebral, anal fin-ray and dorsal fin-ray frequencies by area for S. marinus in the Northwest Atlantic. 
TABLE 1. Statistical data by area for vertebral, anal fin-ray and dorsal fin-ray counts in S. marinus, and probability (P) values associated with $x^{2}$ tests applied to meristic frequencies by sex and depth. ( ${ }^{*}$ indicates significant difference, ${ }^{*}$ indicates highly significant differences, and ... indicates data inadequate for statistical test.)

\begin{tabular}{|c|c|c|c|c|c|c|c|c|}
\hline \multirow{2}{*}{$\begin{array}{c}\text { NAFO } \\
\text { area }\end{array}$} & \multirow{2}{*}{$\begin{array}{l}\text { No. of } \\
\text { fish }\end{array}$} & \multicolumn{4}{|c|}{ Meristic statistics } & \multicolumn{2}{|c|}{$\mathrm{P}\left(x^{2}\right)$ values } & \multirow{2}{*}{$\begin{array}{c}\text { Percent } \\
\text { abnormal } \\
\text { vertebrae }\end{array}$} \\
\hline & & Range & Mode $^{\mathrm{a}}$ & Mean & SE & Sex & Depth & \\
\hline \multicolumn{9}{|c|}{ Vertebral counts ${ }^{b}$} \\
\hline Subarea 0 & 13 & 30 & 30 & 30.00 & 0.000 & $\ldots$ & $\ldots$ & 0.00 \\
\hline Subarea 1 & 131 & $29-30$ & 30 & 29.97 & 0.015 & $1.00^{c}$ & 0.58 & 0.76 \\
\hline Div. $2 \mathrm{~J}$ & 885 & $29-31$ & 30 & 30.04 & 0.009 & 0.44 & 0.21 & 0.78 \\
\hline Div. 3K & 322 & $29-31$ & 30 & 30.01 & 0.013 & 0.63 & 0.71 & 0.62 \\
\hline Div. 3L & 56 & $30-31$ & 30 & 30.16 & 0.050 & $0.38^{c}$ & 0.83 & 3.57 \\
\hline Div. 3M & 650 & $29-31$ & 30 & 30.07 & 0.011 & 0.36 & 0.71 & 0.31 \\
\hline Div. 3N & 109 & $29-31$ & 30 & 30.05 & 0.024 & 0.18 & 0.89 & 0.00 \\
\hline Div. 30 & 48 & $29-31$ & 30 & 30.02 & 0.047 & 0.08 & 0.59 & 0.00 \\
\hline Div. 3P & 1,374 & $29-31$ & 30 & 30.05 & 0.007 & 0.41 & 0.18 & 0.36 \\
\hline Div. 4R & 22 & $29-31$ & 30 & 30.04 & 0.080 & 0.06 & $\cdots$ & 0.00 \\
\hline Total & $3,611^{\mathrm{d}}$ & $29-31$ & 30 & 30.04 & 0.005 & 0.74 & $0.04^{\star}$ & 0.52 \\
\hline \multicolumn{9}{|c|}{ Anal fin-ray counts } \\
\hline Subarea 0 & 13 & $8-9$ & 9 & 8.69 & 0.133 & $0.96^{c}$ & $\ldots$ & \\
\hline Subarea 1 & 130 & $7-10$ & 8,9 & 8.42 & 0.049 & 0.70 & 0.30 & \\
\hline Div. $2 \mathrm{~J}$ & 399 & $7-10$ & 8 & 8.22 & 0.029 & 0.83 & 0.68 & \\
\hline Div. 3K & 34 & $8-9$ & 8,9 & 8.50 & 0.088 & $0.48^{\mathrm{c}}$ & $\ldots$ & \\
\hline Div. 3L & 24 & $7-9$ & 8 & 8.21 & 0.104 & 0.40 & 0.83 & \\
\hline Div. 3M & 81 & $7-10$ & 8 & 8.30 & 0.067 & 0.30 & $<0.01^{\star \star}$ & $\cdot$ \\
\hline Div. $3 \mathrm{~N}$ & 91 & $7-10$ & 8 & 8.23 & 0.061 & 0.52 & 0.55 & \\
\hline Div. 30 & 42 & $7-9$ & 8 & 8.24 & 0.082 & 0.67 & 0.75 & \\
\hline Div. 3P & 560 & $7-10$ & 8 & 8.21 & 0.024 & 0.40 & 0.27 & \\
\hline Div. $4 R$ & 4 & $7-9$ & 8 & 8.00 & 0.408 & $\ldots$ & $\cdots$ & \\
\hline Total & $1,379^{d}$ & $7-10$ & 8 & 8.25 & 0.018 & 0.46 & $<0.01^{* *}$ & \\
\hline \multicolumn{9}{|c|}{ Dorsal fin-ray counts } \\
\hline Subarea 0 & 13 & $15-16$ & 15 & 15.08 & 0.077 & $0.81^{\mathrm{c}}$ & $1.00^{\mathrm{c}}$ & \\
\hline Subarea 1 & 132 & $14-16$ & 15 & 14.95 & 0.044 & 0.05 & 0.80 & \\
\hline Div. 2J & 398 & $13-17$ & 15,14 & 14.58 & 0.035 & 0.86 & 0.76 & \\
\hline Div. 3K & 34 & $14-16$ & 15 & 15.03 & 0.067 & 0.32 & $\ldots$ & \\
\hline Div. 3L & 24 & $14-16$ & 15 & 14.79 & 0.147 & 0.32 & 0.15 & \\
\hline Div. 3M & 81 & $13-16$ & 15 & 14.89 & 0.079 & 0.17 & $<0.01^{\star *}$ & \\
\hline Div. $3 N$ & 91 & $13-16$ & 15 & 14.59 & 0.064 & 0.69 & 0.82 & \\
\hline Div. 30 & 42 & $13-16$ & 15,14 & 14.57 & 0.097 & 0.76 & 0.49 & \\
\hline Div. 3P & 559 & $13-17$ & 15 & 14.62 & 0.029 & 0.32 & 0.91 & \\
\hline Div. $4 \mathrm{R}$ & 4 & $14-15$ & 14 & 14.25 & 0.250 & $1.00^{\mathrm{c}}$ & $\ldots$ & \\
\hline Total & $1,379^{d}$ & $13-17$ & 15 & 14.67 & 0.018 & 0.33 & $<0.01^{\star *}$ & \\
\hline
\end{tabular}

a Where two values are given, first is dominant and the second has a frequency greater than $40 \%$.

- Abnormal vertebrae excluded from analyses.

' Yate's correction applied in $2 \times 2$ table.

d Total includes one specimen from Div. $2 \mathrm{H}$.

TABLE 2. Statistical comparison between meristic characters of $S$. marinus and the beaked redfishes, based on Levene's w-test, the appropriate t-test, and the multivariate F-statistic, with the differences being significant ( $\left(^{*}\right)$ at $P<0.05$, highly significant $\left({ }^{*}\right)$ at $P<0.01$, and not significant (ns) at $P>0.05$.

\begin{tabular}{|c|c|c|c|c|c|c|c|}
\hline \multirow{2}{*}{$\begin{array}{c}\text { NAFO } \\
\text { area }\end{array}$} & \multicolumn{2}{|c|}{ Vertebrae } & \multicolumn{2}{|c|}{ Anal fin rays } & \multicolumn{2}{|c|}{ Dorsal fin rays } & \multirow{2}{*}{$\frac{\text { All meristics }}{\text { Multivariate } F}$} \\
\hline & w-test & t-test & w-test & t-test & w-test & t-test & \\
\hline Subarea $0^{\mathrm{a}}$ & (ns) & $\left({ }^{\star \star}\right)$ & $\left({ }^{*}\right)$ & (ns) & $(* *)$ & $\left({ }^{\star *}\right)$ & (ns) \\
\hline Subarea 1 & $* *$ & $\star \star$ & ns & $*$ & $\star \star *$ & $\star *$ & $\star * *$ \\
\hline Div. 2J & $\star *$ & $\star \star$ & $\star \star$ & ** & $\mathrm{ns}$ & $\star *$ & ** \\
\hline Div. $3 K^{b}$ & ** & $\star \star$ & $\star \star$ & ** & - & - & - \\
\hline Div. 3L & ** & $* *$ & ** & ** & ns & ** & ** \\
\hline Div. 3M & $\star \star$ & 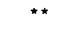 & $\star \star$ & ** & $\star \star$ & $\star \star$ & $\star \star \star$ \\
\hline Div. $3 N$ & ** & $\star \star$ & $\star \star$ & $\star \star *$ & ns & ** & ** \\
\hline Div. 30 & $\star \star$ & $\star \star$ & ns & $\star \star$ & ns & $\star \star$ & $\star \star$ \\
\hline Div. 3P & ** & $\star \star *$ & $* *$ & $\star *$ & $* *$ & ** & $\star \star *$ \\
\hline Div. $4 \mathrm{R}^{\mathrm{a}}$ & $\star \star$ & ** & (ns) & (ns) & (ns) & (ns) & (ns) \\
\hline
\end{tabular}

a Characters in parentheses pertain to small samples of $S$. marinus.

b Dashes indicate lack of beaked redfish specimens. 
Div. 4R (eastern Gulf of St. Lawrence) where the dominant number was 14 (Fig. 1). Like the anal fin-ray averages, the mean dorsal fin-ray counts exhibited a relatively wide range (14.25-15.08), with a decreasing trend from north to south (Table 1).

\section{Comparison between $\mathbf{S}$. marinus and beaked redfishes}

The meristic data for $S$. marinus (Table 1) were compared statistically with similar data for beaked redfishes in tables 3-5 of $\mathrm{Ni}$ (1982). Significant differences between $S$. marinus and beaked redfishes were prevalent for each of the three meristic characters by use of Levene's w-test of variances and the appropriate t-test of mean values and also for the combined characters by use of the transformed multivariate F-statistic (Table 2). The absence of significant differences for some comparisons in Subarea 0 and Div. 4R was probably due to insufficient data for $S$. marinus. Only the variances ( $w$-test) showed no significant differences for anal fin-ray counts in Subarea 1 and Div. 30 and for dorsal fin-ray counts in Div. 2J, 3L, 3N and 3O. Geographic variation in S. marinus was less than in the beaked redfishes (Fig. 2).

\section{Discussion}

Redfish described in this paper were identified by following the criteria of Templeman and Sandeman (1957). A possible error was the misplacement of some small $S$. marinus with the beaked redfishes, but $S$. marinus constituted a minor portion of the overall catches of redfish by research vessels in the LabradorNewfoundland region ( $\mathrm{Ni}$ and McKone, 1983). The meristic data for beaked redfishes are unlikely to be biased by a small number of misclassified S. marinus.

The meristics of S. marinus in the Northwest Atlantic were relatively stable: no sexual difference was found in any area or in all areas combined, and only in Div. 3M was significant depth variation observed for anal and dorsal fin-ray counts (Table 1). For all three meristic characters, significant differences among depth zones for the combined data of all areas imply geographic variation of meristics in $S$. marinus. The area contributing the greatest difference was Div. 3M (Flemish Cap), indicating that the stock of S. marinus there may be distinct from those of adjacent areas. Geographic clines in anal and dorsal fin-ray counts contrast with the stable vertebral counts (Fig. 2).

Barsukov and Zakharov (1972) first described the morphological differences among the North Atlantic redfishes, but they admitted that more intensive investigations were necessary for a definitive solution to the redfish classification problem. $\mathrm{Ni}$ (1982) presented the results of a detailed study of meristics in the beaked redfishes, $S$. mentella and $S$. fasciatus, and this study

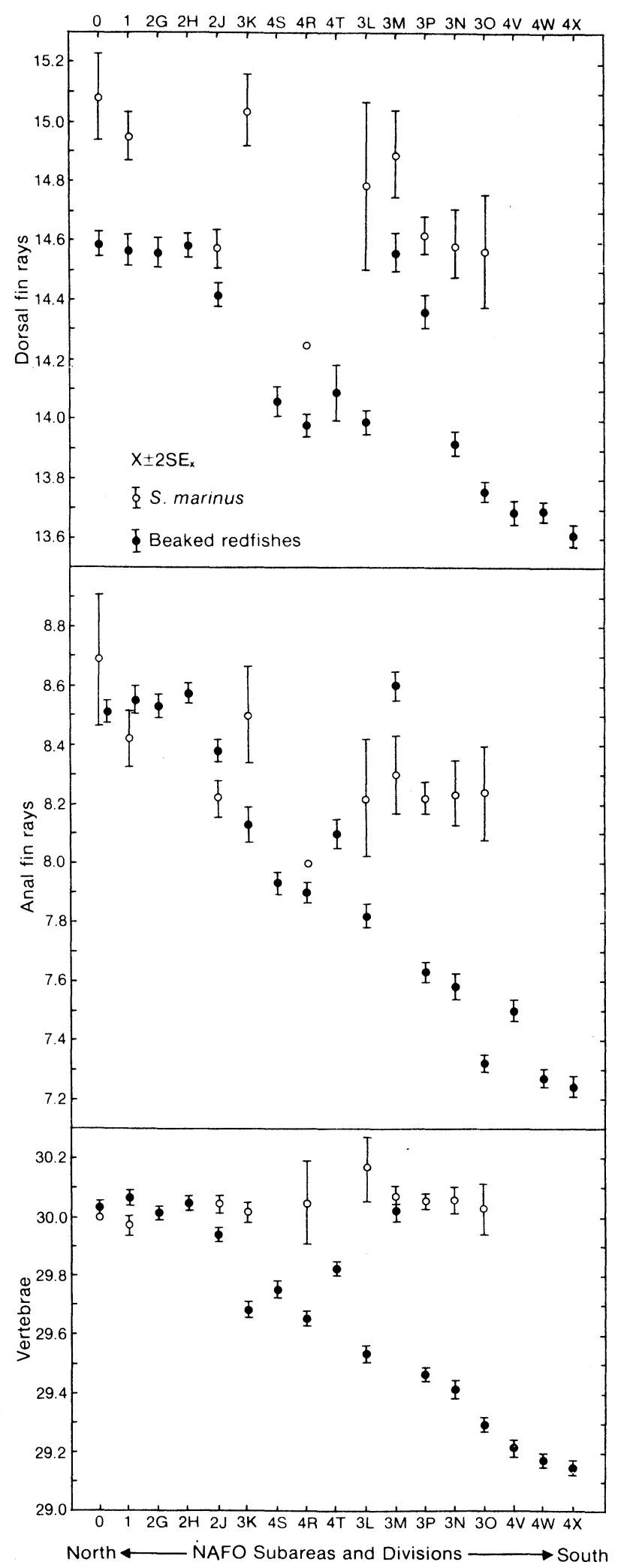

Fig. 2. Geographic variation in average numbers of vertebrae, anal fin rays and dorsal fin rays in S. marinus and beaked redfishes of the Northwest Atlantic. (Horizontal bars represent the $95 \%$ confidence limits.) 
TABLE 3. Statistical data recorded in the literature for meristic frequencies of North Atlantic redfishes: $S$. marinus, $S$. mentella, $S$. fasciatus and S. viviparus.

\begin{tabular}{cllllll}
\hline \hline \multirow{2}{*}{ Area } & \multicolumn{2}{c}{ Vertebrae $^{a}$} & & Anal fin rays & & Dorsal fin rays \\
\cline { 2 - 3 } & No. Mode Mean & & No. Mode Mean & No. Mode Mean & Source \\
\hline
\end{tabular}

\begin{tabular}{|c|c|c|c|c|c|c|c|c|c|c|}
\hline \multicolumn{11}{|c|}{ Sebastes marinus } \\
\hline Barents Sea & 22 & 30 & 29.91 & 244 & 8 & 7.92 & 56 & 15 & 14.54 & Barsukov and Zakharov (1972) \\
\hline Iceland, W. Greenland & 21 & 30 & 29.57 & 26 & 8 & 8.12 & 42 & 14,15 & 14.43 & Barsukov and Zakharov (1972) \\
\hline NAFO Div. 2J,3K,3L & 66 & 30 & 29.92 & 66 & 8 & 8.39 & - & - & - & Barsukov and Zakharov (1972) \\
\hline \multicolumn{11}{|c|}{ Sebastes mentella } \\
\hline Barents Sea & 37 & 30 & 30.14 & 137 & 8 & 8.48 & 80 & 14 & 14.29 & Barsukov and Zakharov (1972) \\
\hline Iceland & 253 & 30 & 30.17 & 282 & 9 & 8.49 & 34 & 15 & 14.65 & Barsukov and Zakharov (1972) \\
\hline Iceland and Greenland & 37 & 30 & 30.27 & 42 & 9 & 8.72 & - & - & - & Barsukov (1972) \\
\hline NAFO Subarea 1 & 146 & 30 & 29.99 & 235 & 9 & 8.53 & 57 & 15 & 14.53 & Barsukov and Zakharov (1972) \\
\hline NAFO Subarea 1 & 546 & 30 & 30.06 & 591 & 9 & 8.55 & 591 & 15 & 14.57 & $\mathrm{Ni}(1982)$ \\
\hline NAFO Subarea 0 & 397 & 30 & 30.02 & 526 & 9 & 8.54 & 153 & 15 & 14.59 & Barsukov and Zakharov (1972) \\
\hline NAFO Subarea 0 & 599 & 30 & 30.03 & 771 & 9 & 8.51 & 771 & 15 & 14.59 & $\mathrm{Ni}(1982)$ \\
\hline NAFO Div. $2 \mathrm{G}$ & 435 & 30 & 30.01 & 825 & 9 & 8.53 & 468 & 15 & 14.56 & $\mathrm{Ni}(1982)$ \\
\hline NAFO Div. $2 \mathrm{H}$ & 948 & 30 & 30.04 & 1,282 & 9 & 8.57 & 983 & 15 & 14.59 & $\mathrm{Ni}(1982)$ \\
\hline NAFO Div. $2 \mathrm{~J}$ & 202 & 30 & 30.04 & 203 & 9 & 8.61 & - & - & - & Barsukov and Zakharov (1972) \\
\hline NAFO Div. 3K & 232 & 30 & 30.03 & 233 & 9 & 8.51 & - & - & - & Barsukov and Zakharov (1972) \\
\hline NAFO Div. 3L & 100 & 30 & 30.03 & 100 & 8 & 8.62 & 100 & 15 & 14.67 & $\mathrm{Ni}(1981 b)$ \\
\hline NAFO Div. 30 & 109 & 30 & 30.10 & 297 & 9 & 8.94 & 42 & 14 & 14.61 & Litvinenko (1974) \\
\hline NAFO Div. 3M,3P & 49 & 30 & 30.00 & 48 & 8 & 8.37 & - & - & - & Barsukov and Zakharov (1972) \\
\hline NAFO Div. 3M,4V & 48 & 30 & 30.02 & 48 & 8 & 8.40 & - & - & - & Barsukov (1972) \\
\hline NAFO Div. $4 R^{b}$ & 5,335 & 30 & 29.65 & 2,205 & 8 & 7.90 & 1,482 & 14 & 13.98 & $\mathrm{Ni}(1982)$ \\
\hline NAFO Div. $4 S^{b}$ & 2,465 & 30 & 29.75 & 1,588 & 8 & 7.93 & 759 & 14 & 14.06 & $\mathrm{Ni}(1982)$ \\
\hline NAFO Div. $4 T^{\mathrm{b}}$ & 2,053 & 30 & 29.82 & 522 & 8 & 8.10 & 219 & 14 & 14.09 & $\mathrm{Ni}(1982)$ \\
\hline
\end{tabular}

\section{Sebastes fasciatus}

\begin{tabular}{|c|c|c|c|c|c|c|c|c|c|c|}
\hline NAFO Div. 2J,3K & 228 & 29 & 29.36 & $232^{\mathrm{c}}$ & 8 & 7.63 & $96^{\mathrm{c}}$ & 14 & 13.79 & Barsukov and Zakharov (1972) \\
\hline NAFO Div. 3L & 99 & 29 & 29.31 & 100 & 7 & 7.02 & 100 & 14 & 13.69 & $\mathrm{Ni}(1981 b)$ \\
\hline NAFO Div. $3 L^{d}$ & 1,743 & 29 & 29.53 & 1,850 & 7,8 & 7.82 & 1,658 & 14 & 13.99 & $\mathrm{Ni}(1982)$ \\
\hline NAFO Div. $3 N^{d}$ & 1,299 & 29 & 29.41 & 1,279 & 7 & 7.58 & 1,274 & 14 & 13.92 & $\mathrm{Ni}(1982)$ \\
\hline NAFO Div. 30 & 1,885 & 29 & 29.29 & 1,993 & 7 & 7.32 & 1,693 & 14 & 13.76 & $\mathrm{Ni}(1982)$ \\
\hline NAFO Div. 30 & 124 & 29 & 29.05 & 124 & 7 & 7.22 & 84 & 14 & 13.63 & Litvinenko (1974) \\
\hline NAFO Div. $3 M, 3 N, 3 O, 3 P$ & 455 & 29 & 29.12 & 455 & 7 & 7.27 & $196^{e}$ & 14 & 13.67 & Barsukov and Zakharov (1972) \\
\hline NAFO Div. $4 V^{t}$ & 1,061 & 29 & 29.21 & 1,239 & 7 & 7.50 & 952 & 14 & 13.69 & $\mathrm{Ni}(1982)$ \\
\hline NAFO Div. $4 W^{t}$ & 2,598 & 29 & 29.17 & 1,608 & 7 & 7.27 & 1,607 & 14 & 13.69 & $\mathrm{Ni}(1982)$ \\
\hline NAFO Div. $4 X^{4}$ & 1,176 & 29 & 29.15 & 1,013 & 7 & 7.24 & 1,014 & 14 & 13.61 & $\mathrm{Ni}(1982)$ \\
\hline NAFO Div. $4 \mathrm{~W}, 5 \mathrm{Z}$ & 447 & 29 & 29.19 & 489 & 7 & 7.22 & $106^{9}$ & 14 & 13.73 & Barsukov and Zakharov (1972) \\
\hline
\end{tabular}

$\begin{array}{lrrrrrrrrrr}\text { Norway Coast } & 60 & 29 & 29.00 & 88 & 7 & 7.02 & 84 & 13 & 13.42 & \begin{array}{c}\text { Barsukov and Zakharov (1972) } \\ \text { Rockall Bank }\end{array} \\ \text { Iceland } & 48 & 29 & 29.00 & 50 & 7 & 6.80 & - & - & - & \text { Barsukov and Zakharov (1972) } \\ \text { Barsukov and Zakharov (1972) }\end{array}$

a Where necessary, data were adjusted to exclude urostyle.

e Samples from Div. 30 and 3P only.

b Samples contain some $S$. fasciatus from shallow water.

Samples contain few S. mentella from deep water.

c Samples from Div. 3K only.

a Samples contain some S. mentella from deep water.

of the sexual, depth and geographic variation of meristics in S. marinus completes the overall investigation of meristic characters in the Northwest Atlantic redfishes. It is easier to separate $S$. marinus from beaked redfishes (Templeman and Sandeman, 1957) by morphometric characters than to separate $S$. mentella from $S$. fasciatus. This study confirms the hypothesis of Baruskov and Zakharov (1972) on differences and similarities in meristics among the redfish species. S. marinus is similar to $S$. mentella in having 30 vertebral (excluding the urostyle), 8 anal fin-ray and 15 dorsal fin-ray elements, whereas $S$. fasciatus usually has 29,7 and 14 elements respectively, these latter counts being similar to those in the European redfish, S. viviparus (Table 3 ). It was also found that $S$. marinus has less variation in anal and dorsal fin-ray counts than the beaked redfishes.

With regard to the common name of $S$. marinus, NAFO follows the Fisheries and Agricultural Organization of the United Nations (FAO) World List of Species and uses "golden redfish" as the common name for this species, in reference to the orange red or golden red color, instead of "ocean perch" or "redfish" as in the 
4th edition of "A list of common and scientific names of fishes from the United States and Canada" (American Fisheries Society, 1980). This colorful vernacular name is appropriate because it follows the principles governing the selection of common names.

\section{Acknowledgements}

I am grateful to W. Templeman and E. J. Sandeman for the privilege of using previously collected data, to C. E. Bourgeois for assembling the illustrations, and to G. R. Lilly, D. B. Atkinson, R. Wells, A. T. Pinhorn, and V. M. Hodder for their comments during the preparation of the manuscript.

\section{References}

AMERICAN FISHERIES SOCIETY. 1980. A list of common and scientific names of fishes from the United States and Canada (4th edition). Spec. Publ. Amer. Fish. Soc., N. 12, 174 p.

BARSUKOV, V. V. 1968. The systematic relationship of redfishes of the genus Sebastes of the Northwest Atlantic. Doklady Akad. Nauk SSSR, 183: 479-482. (Transl. from Russian in Dokl. Biol. Sci., 183: 734-747.)

1972. Systematics of the Atlantic redfishes. Tr., PINRO, 28: 128-142. (Fish. Res. Bd. Canada Transl. Ser., No. 2531, 1973.) BARSUKOV, V. V., and G. P. ZAKHAROV. 1972. Morphological and biological characteristics of the American redfish, Tr., PINRO, 28: 143-173. (Fish. Res. Bd. Canada Transl. Ser., No. 2488, 1973.) DIXON, W. J., M. B. BROWN, L. ENGELMAN, J. W. FRANE, M. A. HILL, R. I. JENNRICH, and J. D. TOPOREK. 1981. BMDP statistical softward, 1981. Univ. Calif. Press, Berkeley, CA.

LITVINENKO, N. N. 1974. Coloration and other morphological characters distinguishing juvenile Sebastes fasciatus from juvenile $S$. mentella (Scorpaenidae). J. Ichthyol., 14: 591-595.

1980. The structure, function and origin of the drumming muscles in the North Atlantic ocean perches of the genus Sebastes (Scorpaenidae). J. Ichthyol., 20: 89-98.

MORRISON, D. F. 1976. Multivariate statistical methods. McGraw-Hill Book Co., Toronto, Canada, 415 p.

NI, I-H. 1981a. Separation of sharp-beaked redfishes, Sebastes fasciatus and S. mentella, from northeastern Grand Bank by morphology of extrinsic gasbladder musculature. J. Northw. Atl. Fish. Sci. 2: 7-12.

1981b. Numerical classification of sharp-beaked redfishes, Sebastes fasciatus and S. mentella. Can. J. Fish. Aquat. Sci., 38: 873-879.

1982. Meristic variation in beaked redfishes, Sebastes mentella and S. fasciatus, in the Northwest Atlantic. Can. J. Fish. Aquat. Sci., 39: 1664-1685.

NI, I-H, and W. D. McKONE. 1983. Distribution and concentration of redfishes, in Newfoundland and Labrador waters. NAFO Sci. Coun. Studies, 6: 7-14

TEMPLEMAN, W. 1959. Redfish distribution in the North Atlantic. Bull. Fish. Res. Bd. Canada, 120: 1-173.

1980. Incidence of subcaudal melanophores in pre-extrusion larvae of redfish species in the Newfoundland-Labrador area. $J$. Northw. Atl. Fish. Sci., 1: 7-19.

TEMPLEMAN, W., and E. J.SANDEMAN. 1957. Two varieties of redfish in the Newfoundland area. Fish. Res. Bd. Canada, Atlant. Prog. Rep., 66: 20-23. 